\title{
How does nursing research differ internationally? A bibliometric analysis of six countries
}

\author{
Mike Thelwall PhD in Pure Mathematics, Professor of Data Science, Leader of the Statistical \\ Cybermetrics Research Group (1) । \\ Amalia Mas-Bleda PhD in Library and Information Sciences, Social Media Content Analysis \\ Postdoctoral Researcher
}

School of Mathematics and Computing, University of Wolverhampton,

Wolverhampton, UK

\section{Correspondence}

Mike Thelwall, School of Mathematics and Computing, University of Wolverhampton, Wulfruna Street, WV1 1LY, Wolverhampton, UK.

Email: m.thelwall@wlv.ac.uk

\begin{abstract}
Background: International nursing research comparisons can give a new perspective on a nation's output by identifying strengths and weaknesses.

Aim: This article compares strengths in nursing research between six mainly English-speaking nations (Australia, Canada, Ireland, New Zealand, United Kingdom and United States).

Methods: Journal authorship (percentage of first authorship by nationality) and article keywords were compared for Scopus-indexed journal articles 2008-2018. Three natural language processing strategies were assessed for identifying statistically significant international differences in the use of keywords or phrases. Results: Journal author nationality was not a good indicator of international differences in research specialisms, but keyword and phrase differences were more promising especially if both are used. For this, the part of speech tagging and lemmatisation text processing strategies were helpful but not named entity recognition. The results highlight aspects of nursing research that were absent in some countries, such as papers about nursing administration and management. Conclusion: Researchers outside the United States should consider the importance of researching specific patient groups, diseases, treatments, skills, research methods and social perspectives for unresearched gaps with national relevance. From a methods perspective, keyword and phrase differences are useful to reveal international differences in nursing research topics.

KEYWORDS

bibliometrics, natural language processing, nursing, research priorities, topic differences
\end{abstract}

\section{SUMMARY STATEMENT}

What is already known about this topic?
- There are international differences in nursing research topics.

- Some countries specialize in individual nursing areas and have gaps in other areas.

This is an open access article under the terms of the Creative Commons Attribution License, which permits use, distribution and reproduction in any medium, 
What this paper adds?

- Word frequency-based analyses of article titles, abstracts and keywords can point to international differences in research specialisms; various natural language processing techniques can identify additional topics.

- Comparing author nationality proportions (based on first author affiliations) between journals does not help to reveal national topic specialisms.

- A list of nursing research topics that are more common in the United States than in other English-speaking nations is provided.

The implications of this paper:

- Researchers can find a list of areas where there may be national gaps.

\section{1 | INTRODUCTION}

Identifying gaps in a nation's nursing research allows international perspectives to inform national research and practice. The current paper investigates international differences in nursing topics both to assess the best methods for this task and to report findings from a largescale comparison.

Research fields are often studied using network analysis techniques, including author co-citation analysis (Bu, Ni, \& Huang, 2017; White \& McCain, 1998) or co-word maps (e.g., based on keywords or titles and/or abstract terms that occur in multiple papers; Waltman, Van Eck, \& Noyons, 2010). Clusters in these maps can point to topics of interest. Alternatively, topic modelling can be applied to keywords or titles/abstracts to identify the main underlying topics within a collection of articles (Talley et al., 2011). These methods produce term clusters that may reflect research themes or topics. They are unsuitable for comparing national publications, however, for several reasons. First, the human interpretation of the clusters or sets of terms is unreliable for identifying topics because patterns occur amongst a set of words even when they are randomly generated because of language ambiguity (Leydesdorff \& Nerghes, 2017). Second, clustering and topic modelling rely on arbitrary thresholds so that two similar datasets can produce different topics or maps. Third, maps do not reveal whether differences are statistically significant. Comparisons of maps or topics are therefore unreliable for detecting fundamental differences.

\section{1 | Background: Nursing bibliometrics research}

Few prior studies have compared national contributions to nursing research through a statistical bibliometric approach, so this background section systematically characterizes bibliometric studies of nursing research to contextualize the current paper (see also Kokol \&
TABLE 1 Analyses reported in 75 bibliometric studies of nursing 2013-2018

\begin{tabular}{|ll|}
\hline Analysis & Articles \\
\hline Publication volume trends over time & 43 \\
\hline Journals identified, analysed, ranked or JIFs mentioned & 36 \\
\hline Country focus & 35 \\
\hline $\begin{array}{l}\text { Research topics identified } \\
\text { Geographic or institutional breakdown reported (e.g., top } \\
\text { publication area was London) }\end{array}$ & 32 \\
\hline $\begin{array}{l}\text { Academics identified or their properties (e.g., gender and } \\
\text { occupation) }\end{array}$ & 31 \\
\hline $\begin{array}{l}\text { Methods identified } \\
\text { Citations mentioned (not JIF, not co-citations), including } \\
\text { h-index, average or total citations }\end{array}$ & 25 \\
\hline $\begin{array}{l}\text { Collaboration/co-authorship investigated } \\
\text { Funding investigated }\end{array}$ & 23 \\
\hline $\begin{array}{l}\text { Extracted specific properties (e.g., contains ethics } \\
\text { statements) }\end{array}$ & 8 \\
\hline $\begin{array}{l}\text { References investigated } \\
\text { Altmetrics investigated }\end{array}$ & 7 \\
\hline
\end{tabular}

Abbreviation: JIF, journal impact factor.

The query used was as follows: TITLE-ABS-KEY (nurs*) AND DOCTYPE (ar) AND SRCTYPE(j) AND (TITLE-ABS-KEY (bibliometric*) OR TITLE-ABS-KEY (scientometric*) OR TITLE-ABS-KEY (citation*) OR TITLE-ABS-KEY (altmetric*) OR TITLE-ABS-KEY (webometric*) OR TITLE-ABS-KEY("impact factor")).

Vošner, 2019). Bibliometric studies of nursing were sought using a Scopus query on 16 September 2018, producing 839 articles (see Table 1 for the query). It was designed to match bibliometric studies with nursing as a main component. Because the focus is on mainly English-speaking nations, non-English terms, such as 'enfermería', were excluded. Studies published after 2012 were chosen for relevance, then examined and filtered to identify and categorize relevant articles (Table 1). Of the 75 bibliometric studies, most were journal articles (62) or theses/dissertations (8). The most common method used to identify topics or methods was a form of (human) content analysis (29). The most common analysis was 'publication volume trends over time', reported in 43 articles. Supporting Information S1 lists the 75 bibliometric studies.

Few studies have compared nursing topics between nations, although several have partly summarized the main research topics of a country through a content analysis of its journal articles (Borracci \& Rabhansl de Desmery, 2013), master's dissertations (Arzuaga, Correa, \& Florez-Torres, 2015; da Silva et al., 2016) or theses (Backes et al., 2013; Baggio, Rodrigues, Erdmann, Barbieri Figueiredo, \& Vieira, 2014; Ferreira, Pereira, Martins, \& Barbieri-Figueiredo, 2016; Wilkes, Cummings, Ratanapongleka, \& Carter, 2015). Other studies have used content analyses of journal articles to characterize aspects of a research field within a country or region (Bagnasco et al., 2019; de Holanda, Lira, Galvão, Damasceno, \& de Araujo, 2013; Sweileh, Huijer, Al-Jabi, Sa'ed, \& Sawalha, 2019; Tizón Bouza et al., 2015; Wilkes \& Jackson, 2011; Ying, Jie, Ping, \& Lingjuan, 2015; Yue, Pi, \& 
Fan, 2016) or have used a Delphi study to canvas expert opinion (Browne, Robinson, \& Richardson, 2002; Drennan et al., 2007). Other country-based studies have explored trends in nursing research by analysing nursing research submitted to national public funding programmes (Cecil, Thompson, \& Parahoo, 2006; Dupin, Chami, Petit dit Dariel, Debout, \& Rothan-Tondeur, 2013; Martín-Arribas et al., 2009) or have analysed the influence of funding on an international scale (Kokol, Železnik, Završnik, \& Blažun Vošner, 2019). One prior, but relatively old, international comparative investigation of nursing topics analysed 1,072 papers in eight nursing journals 2005-2006, finding that studies of nurses were more common in Australia, Canada and Europe, whereas authors from the United States and Asian countries focused more on the patient-centred perspective (Polit \& Beck, 2009).

A content analysis has compared the nursing research topics from a single specialism, disaster nursing, in a single country with the rest of the world. By manually classifying the content of 1,384 articles in English and Chinese and numerically comparing the proportions between China and the rest of the world, it found that Chinese research used a narrower range of methods, did not cover all types of disaster well and tended to ignore some important aspects of disaster nursing, such as preparedness (Zhang et al., 2018).

Nine studies used term frequencies to investigate research patterns in nursing without making comparisons. The most common technique was co-word analysis to generate network diagrams of related terms, identifying themes (e.g., Zhao et al., 2018). These found five themes (e.g., health care drivers) within practice research (Benton, Cusack, Jabbour, \& Penney, 2017), topics and trends within chronic disease self-management ( $\mathrm{Lu}, \mathrm{Li}, \&$ Arthur, 2014), funding topics within nursing informatics (Kokol \& Vošner, 2017), topics covered by a nursing journal (Benton \& Alexander, 2016; Železnik, Blažun Vošner, \& Kokol, 2017), topics within Chinese evidence-based nursing (Zhao et al., 2018), Turkish nursing topics (Damar, Bilik, Ozdagoglu, Ozdagoglu, \& Damar, 2018) and topics within occupational licensure (Benton et al., 2018).

A co-word and co-citation analysis has compared the role of nurses in health care transformations between four countries (Australia, Canada, United Kingdom and United States), producing multiple large network visualizations. Separate co-word maps were produced for each country, each of which was used to manually identify clusters. These clusters were then labelled with theme descriptions (e.g., for the United States: affordable health care financing; delivery models and associated quality dimensions, educational reform; maternal and clinical service; advanced practice; measures; and organizational level nursing contribution), and the country-specific clusters were compared (Benton, Trautman, \& Swick, 2017). This gives useful comparisons but no statistical support for any conclusions.

This paper introduces simple methods to identify statistical differences between two document sets and compares them before reporting the results of the most promising approach. The methods are (a) comparison of the number of articles published in relevant journals, using journal specialisms as a proxy for topic specialisms, and (b) statistical comparison of terms used in article titles, abstracts and/or keywords with or without natural language processing (NLP). The first three research questions address methods issues and the final question represents the overall aim. For this question, the US set of papers was chosen as the reference case because it had the most articles and could therefore give the most powerful statistical results.

1. How informative is counting national shares in journals about national nursing research specialisms?

2. Does treating multiword keyword terms as individual words give more word frequency difference information from keyword comparisons?

3. Which, if any, of part of speech (POS) tagging, lemmatisation or named entity recognition (NER) give more useful term frequency differences for titles and abstracts than simple word frequency comparison?

4. Which types of nursing research are more prevalent in the United States than in other countries?

\section{2 | METHODS}

This research design investigated topic differences for nursing research between large English-speaking nations using three methods (POS tagging, lemmatisation and NER) and evaluated the results.

\section{1 | Search strategy}

Scopus was chosen as the bibliometric database because it has wider coverage than the Web of Science (Falagas, Pitsouni, Malietzis, \& Pappas, 2008). All journal articles from all 24 Scopus nursing categories published between 2008 and 2018 were downloaded with the Scopus Applications Programming Interface (API) on 10-11 October 2018 with queries of the following form, where 2914 is the code for Medical and Surgical Nursing and the publication year was sent as a separate parameter.

Scopus usually classifies articles according to their publishing journal. Because it often classifies journals into multiple categories, it returned many unrelated articles from non-nursing journals. Initial explorations of the data suggested that this issue was prevalent and would render the method meaningless. To avoid the problem of largely irrelevant journals, all journals were removed unless their titles included 'nurs' or 'midwi'. Inspection of the list of journal names suggested that these were sufficient to identify all large and medium sized English-language journals in Scopus focusing on nursing. After removing duplicates, the final data set consisted of 95,288 unique journal articles in nursing journals from Scopus 2008-2018 (Table 2).

The country affiliation of the first author (usually the main contributor: Larivière et al., 2016) was identified for each article. Six countries where English is the most common native language (Australia, Canada, Ireland, New Zealand, United Kingdom and United States) were chosen. This excluded countries where English is a common academic language but may not be spoken by nurses (e.g., India and 
TAB LE 2 The number of Scopus journal articles 2008-2018 in a Scopus nursing narrow field and a journal with a name containing 'nurs' or 'midwi'

\begin{tabular}{|lcc|}
\hline Field & All articles & $\begin{array}{c}\text { Articles in Nurs/ } \\
\text { Midwi journals }\end{array}$ \\
\hline Nursing (all) & 66,613 & 39,115 \\
\hline Nursing (miscellaneous) & 7,427 & 3,343 \\
\hline Advanced and specialized nursing & 30,663 & 11,681 \\
\hline Assessment and diagnosis & 4,964 & 2,690 \\
\hline Care planning & 2,902 & 0 \\
\hline Community and home care & 12,638 & 3,004 \\
\hline Critical care nursing & 8,260 & 5,797 \\
\hline Emergency nursing & 16,316 & 5,332 \\
\hline Fundamentals and skills & 7,389 & 4,088 \\
\hline Gerontology & 20,494 & 2,321 \\
\hline Issues, ethics and legal aspects & 17,397 & 2002 \\
\hline Leadership and management & 14,404 & 7,059 \\
\hline LPN and LVN & 10,297 & 4,855 \\
\hline Maternity and midwifery & 11,230 & 5,986 \\
\hline Medical and surgical nursing & 10,168 & 4,061 \\
\hline Nurse assisting & 1,567 & 477 \\
\hline Nutrition and dietetics & 100,698 & 191 \\
\hline Oncology (nursing) & 7,596 & 4,352 \\
\hline Pathophysiology & 0 & 0 \\
\hline Paediatrics & 9,767 & 4,000 \\
\hline Pharmacology (nursing) & 3,270 & 384 \\
\hline Psychiatric mental health & 16,724 & 5,097 \\
\hline Research and theory & 3,157 & 2,440 \\
\hline Review and exam preparation & 3,090 & 2,229 \\
\hline Total (including duplicates) & 387,031 & 120,504 \\
\hline & & \\
\hline
\end{tabular}

Note: Some articles are in multiple categories.

Abbreviations: LPN, licenced practical nurse; LVN, licenced vocational nurse.

South Africa). The coverage of Scopus in these countries may have a different nature to that in mainly native English-speaking nations (Table 3). Articles from these six countries comprised $65 \%$ of the nonduplicate articles. No non-English articles were found.

\section{2 | Data extraction}

Article abstracts were processed to remove copyright statements (e.g., Copyright Elsevier Ltd) at the beginning or end and text associated with structured abstracts (e.g., 'Background:').

A table of 1,736 British/US spellings (plus plurals) was used to convert British to US English (for articles with all author affiliations). Without this, topic differences could be produced by spelling differences (e.g., labour/labor). The list did not include phrases that are more typical for the United States or the United Kingdom or
TAB LE 3 The number of Scopus journal articles 2008-2018 in a Scopus nursing narrow field and a journal with a name containing 'nurs' or 'midwi' in the data set with a first author from six mainly native English-speaking countries

\begin{tabular}{|lccc|}
$\begin{array}{l}\text { First author } \\
\text { country }\end{array}$ & Articles & $\begin{array}{l}\text { Articles with } \\
\text { keywords }\end{array}$ & $\begin{array}{c}\text { Articles with } \\
\text { abstracts }\end{array}$ \\
\hline Australia & 5,292 & 4,538 & 5,021 \\
\hline Canada & 3,758 & 2,684 & 3,344 \\
\hline Ireland & 978 & 840 & 920 \\
\hline New Zealand & 612 & 432 & 479 \\
\hline United Kingdom & 10,234 & 7,212 & 8,561 \\
\hline United States & 41,065 & 21,583 & 31,833 \\
\hline Total & 61,939 & 37,289 & 50,158 \\
\hline
\end{tabular}

Note: A few articles had no articles or keywords reported in Scopus.

words/phrases that are unique to other countries. Using the list nevertheless reduced the need for human checking.

Term comparisons might be improved through NLP techniques that interpret words in context. POS tagging (Brill, 1992) involves identifying the probable part of speech (e.g., verb or noun) of each word in a sentence. This is typically marked by adding the part of speech to the end of the word (e.g., like could be a verb, tagged: like_VBP or an adjective, tagged: like_JJ). Comparing POS-tagged words may therefore reveal finer-grained differences. In contrast, NER identifies named entities (e.g., National Health Service), including multiword phrases (Nadeau \& Sekine, 2007). Comparing the frequency of named entities rather than their constituent words can also give finer-grained information and reduce word ambiguity. In contrast, lemmatisation (Straková, Straka, \& Hajič, 2014) assigns each word to its lexical root, merging multiple words into a single lemma (e.g., am and is replaced with lemma be). Lemmatisation is more powerful than stemming, which only removes word endings (e.g., wear, wears and wearing would all be stemmed to wear but not the related word wore). Comparisons between lemmas are less fine-grained but more statistically powerful.

The POS tagging, NER and lemmatisation used the Stanford CoreNLP parser (Manning et al., 2014) on article titles, abstracts and keywords.

\section{3 | Statistical analysis}

For the first research question, the total number of first authored articles from each journal and country was tallied and the percentage from each country was calculated.

A $2 \times 2$ chi-square test was used to compare the frequency of terms in the US set of papers compared with the remaining group for Research Question 4. The United States was chosen as the reference case because it had the most articles and could therefore give the most powerful statistical results. For example, the term interdisciplinary occurred in 52 of the keywords of 21,583 US articles with 
keywords (0.24\%) and in 12 of 15,706 for the other countries (0.08\%), and this difference was shown to be statistically significant, with a Chi-square value of 14.4 .

The hypothesis test assesses the null hypothesis that the US sample was taken from an apparent population with the same population mean as the non-US sample. Here, an apparent population (Berk, Western, \& Weiss, 1995) is the set of articles that could reasonably have been written in the countries under the same circumstances. This relies on the assumption that the choice of research topic for each article is independent of the choice for other articles within a set. However, this may not be true because successful studies can trigger follow-up research and an author may choose to publish a set of related articles. The test is therefore a heuristic rather than robust.

The chi-square test was repeated for all terms in all article keywords, titles and abstracts. This was set to produce multiple tests (e.g., 15,802 keywords or phrases), and many will therefore be positive due to chance, without any underlying (apparent population) international differences. To preserve the familywise error rate, the Benjamini-Hochberg procedure (Benjamini \& Hochberg, 1995) was used. This increases the threshold for a statistically significant result in a parsimonious manner. In the above case, the Chi-square test value of 14.4 was not significant after the threshold was increased.

\section{RESULTS}

\section{1 | Research Question 1: Journal shares}

This section compares the nationality of first authors between journals. Most of the largest journals are dominated by the United States or the United Kingdom (Table 4). Others were dominated by Australia (77\% of the 497 Contemporary Nurse articles had an Australian first author). Canadian Journal of Nursing Research was dominated by Canada ( $92 \%$ of the 142 articles with a Canadian first author), and Kai Tiaki Nursing New Zealand had $86 \%$ of 74 articles with a New Zealand first author. For Ireland, World of Irish Nursing magazine had six Scopus-indexed documents in 2008-2018, one of which was classified as a journal article. Thus, nursing journals are delimited primarily by author nationality rather than specialism.

\section{2 | Research Question 2: Keyword terms: multiword phrases versus individual words}

A key phrases comparison found 130 words or phrases that were statistically significant $(p<.05)$, including 74 multiword phrases, compared with 244 individual keywords (Table 5). Many key phrases

TAB LE 4 The percentage of nursing articles with first authors from six countries of all articles in the journal from those six countries

\begin{tabular}{|c|c|c|c|c|c|c|c|}
\hline Journal & Aus. & Can. & Ire. & NZ & UK & USA & Articles \\
\hline Nursing & $0 \%$ & $1 \%$ & $0 \%$ & $0 \%$ & $0 \%$ & $98 \%$ & 1,409 \\
\hline Journal of Advanced Nursing & $22 \%$ & $13 \%$ & $4 \%$ & $2 \%$ & $34 \%$ & $25 \%$ & 1,294 \\
\hline Nurse Education Today & $28 \%$ & $8 \%$ & $5 \%$ & $2 \%$ & $40 \%$ & $17 \%$ & 1,188 \\
\hline Journal of Nursing Education & $2 \%$ & $9 \%$ & $0 \%$ & $1 \%$ & $0 \%$ & $87 \%$ & 1,080 \\
\hline Clinical Journal of Oncology Nursing & $1 \%$ & $3 \%$ & $0 \%$ & $0 \%$ & $0 \%$ & $95 \%$ & 975 \\
\hline Journal of Nursing Administration & $1 \%$ & $4 \%$ & $0 \%$ & $0 \%$ & $0 \%$ & $95 \%$ & 925 \\
\hline Journal of Pediatric Nursing & $2 \%$ & $5 \%$ & $1 \%$ & $0 \%$ & $2 \%$ & $90 \%$ & 862 \\
\hline Midwifery & $35 \%$ & $5 \%$ & $6 \%$ & $3 \%$ & $40 \%$ & $11 \%$ & 831 \\
\hline Nurse Practitioner & $0 \%$ & $2 \%$ & $0 \%$ & $0 \%$ & $0 \%$ & $98 \%$ & 751 \\
\hline Journal for Nurse Practitioners & $1 \%$ & $1 \%$ & $0 \%$ & $0 \%$ & $0 \%$ & $97 \%$ & 742 \\
\hline Journal of Emergency Nursing & $0 \%$ & $3 \%$ & $0 \%$ & $0 \%$ & $1 \%$ & $95 \%$ & 734 \\
\hline Oncology Nursing Forum & $3 \%$ & $10 \%$ & $0 \%$ & $0 \%$ & $2 \%$ & $85 \%$ & 732 \\
\hline Nurse Education in Practice & $33 \%$ & $9 \%$ & $7 \%$ & $2 \%$ & $34 \%$ & $15 \%$ & 682 \\
\hline British Journal of Community Nursing & $1 \%$ & $1 \%$ & $4 \%$ & $0 \%$ & $91 \%$ & $3 \%$ & 672 \\
\hline International Journal of Nursing Practice & $62 \%$ & $5 \%$ & $3 \%$ & $3 \%$ & $10 \%$ & $17 \%$ & 281 \\
\hline
\end{tabular}

Note: Values above 50\% are highlighted. The 20 journals with the most Scopus articles from these countries 2008-2018 are shown, plus International Journal of Nursing Practice. 
TAB LE 5 Number of statistically significant terms found by term frequency comparisons applied to keywords, titles and abstracts

\begin{tabular}{|l|c|}
\hline Processing & $\begin{array}{l}\text { Statistically } \\
\text { significant terms } \\
\text { (multiword phrases) }\end{array}$ \\
\hline Keywords (e.g., nursing and education) & 244 \\
\hline Key phrases (e.g., nursing_education) & $130(74)$ \\
\hline Title and abstract terms & 578 \\
\hline Title and abstract terms, POS tagged & 729 \\
\hline Title and abstract terms, lemmatised & 572 \\
\hline Title and abstract terms with NER & $558(27)$ \\
\hline Title and abstract terms with NER & $540(28)$ \\
\hline and lemmatised & \\
\hline
\end{tabular}

Abbreviations: NER, named entity recognition; POS, part of speech.

were more informative than their component words, including African_American, electronic_health_record and quality_improvement.

Some phrases covered concepts not represented by any statistically significant keywords, such as nursing_education, because no education synonym was a statistically significant keyword, although educate was.

Some keywords represented concepts that were not present in any statistically significant key phrases. Baccalaureate was statistically significant in the keyword set, and no phrase containing the term was statistically significant. Phrases containing the term that were not statistically significant included baccalaureate_program, baccalaureate_education, baccalaureate_nursing_education and baccalaureate_nursing_student. Another example is hematopoietic (a type of stem cell), which was a statistically significant keyword, but key phrases containing this term were not (e.g., hematopoietic stem_cell_transplantation).

Thus, although key phrases are more informative than keywords, both methods capture concepts that the other misses. The answer to Research Question 2 is therefore that treating multiword keyword terms both as individual and multiwords are helpful in providing information.

\section{3 | Research Question 3: Title and abstract terms}

Similar numbers of statistically significant terms were found by term frequency comparisons applied to the title and abstract terms with all methods except POS tagging (Table 5). The POS tags increased the number of statistically significantly terms by about 150 .

\subsection{1 | POS tags}

POS tagging increased the number of statistically significant terms. This partly occurred because the same concept was replicated in the same word with different parts of speech. The most common cause was singular and plural terms (e.g., depression_NN and
depression_NNP), but there were other causes (e.g., adjective and noun: oncology_JJ, oncology_NN and oncology_NNP).

In some cases, a POS-tagged term was statistically significant, despite the non-POS equivalent being insignificant in the standard set (e.g., education_NNP but not education). Sometimes, related terms were statistically significant in the standard set (e.g., educate in the previous example). In other cases, this did not occur (e.g., end-oflife_NNP and feedings_NN). Thus, POS tagging can identify new significant concepts not present in the standard set.

\subsection{2 | Lemmatisation}

Lemmatisation slightly reduced the number of statistically significant terms. By conflating terms representing the same concept (e.g., earn and earned) it can increase the power of the concept and eliminate concept redundancy in the list. There were a few cases where lemmatised terms were statistically significant when related terms were not in the standard list (e.g., insure and mandate). There were few cases of the opposite, with non-lemmatised terms being statistically significant but the lemmatised equivalent not being so (e.g., rehospitalization and analyse).

\subsection{3 | Named entity recognition}

NER reduced the number of statistically significant terms by a small amount but added 27 multiword phrases. These phrases were all geographically derived rather than giving insights into international differences, as the following categorization shows.

- US legislation and initiatives: Affordable Care Act, (Quality and) Safety Education for Nurses.

- US ethnic groups: African American, Asian American, Korean American, Mexican American.

- US organizations: American Association of Colleges of Nursing, American Nurses Association, American Organization of Nurse Executives, Oncology Nursing Society.

- US institutions: American Nurses Credentialing Center, Centers For Disease Control and Prevention, Centers For Medicare, Food and Drug Administration, Institute of Medicine, Joint Commission, [Centers for Medicare and] Medicaid Services, National Institutes of Health, New York Heart Association, Robert Wood Johnson Foundation, Veterans Health Administration.

- US geographic locations: Midwestern United States, New Jersey, New York, New York City, North Carolina, United States.

\section{4 | Research Question 4: Summary of research topics that are more common in the United States}

This section focuses on the 130 key phrases because these give a relatively concise and precise list of terms that are more used in nursing 
articles from the United States compared with other English-speaking nations. These were manually clustered into 15 related groups for ease of interpretation. All terms listed inside brackets are arranged in decreasing order of statistical significance. Although the method used could identify terms that were relatively common or relatively uncommon in US nursing research, it only identified the former kind. No terms pointed to topics less researched in the United States because the topics would have had to be relatively popular in all five other countries, which did not occur.

- Age group or patient group: Several patient types are more mentioned in the United States, suggesting that research into these groups is more prevalent (paediatric, adolescent, college student, veteran, older adult, geriatric and women).

- Biochemistry and genetics: Nursing research in the United States seems to be more likely to focus on factors underlying diseases (genetic, genomic, cytokine and cortisol).

- Disease/illness/health problem/symptoms: Many diseases are discussed more in the United States, despite most affecting the countries analysed similarly (heart failure, HIV, obesity, depressive symptom, symptom, biomarker, hypertension, sickle cell disease, childhood obesity, depression, cognition, sleep, premature infant, fatigue, sexual assault, posttraumatic stress disorder, human papillomavirus, inflammation, HPV, HIV prevention, fall prevention, traumatic brain injury, prematurity, cervical cancer, intimate partner violence, substance abuse, asthma, AIDS, breast cancer, unintended pregnancy, preeclampsia, rape and sleep disturbance).

- Ethnicity or ethnic sensitivity: It is not surprising that terms related to US demographics are less used in other English-speaking nations (African American, Hispanic, Latino, African American women, Asian American, Mexican American, Korean American and black). Two terms are not demographic specific but relate to strategies in the United States for effective nursing of multicultural populations (acculturation and cultural competency).

- Location for nursing or type of nursing: Except for the last example, these are due to US-specific terminology (high school, NICU [neonatal intensive care unit] and primary care).

- Nurse education/training: Nursing education seems to have a focus in the United States (nursing education, teaching strategies, graduate nursing education and faculty [a term less used outside the United States] development), and some terms point to the organization of education (QSEN [Quality and Safety Education for Nurses]) or US-specific educational strategies (standardized patient, service-learning and simulation).

- Nurse skills, tasks, competencies and strategies: General nursing skills seem to be more commonly referenced in the United States (evidence-based practice, measurement, patient education, holistic nursing and safe patient handling).

- Nursing administration or management: There are many relatively unique administration-related terms for the United States, presumably because countries organize health systems differently (electronic health record, quality improvement, emergency preparedness, shared governance, care coordination, nurse staffing, electronic medical record, Omaha system [taxonomy designed to describe client care] and process improvement).

- Nursing qualification or role: There are international differences in terminology for roles and qualifications (Advanced Practice Nurse, Nurse Practitioner, APN [Advanced Practice Nurse], Advanced Practice Registered Nurse, Doctor Of Nursing Practice, school nurse, nursing faculty, clinical nurse leader, certification, school nursing, NCLEX-RN [National Council Licensure Examination for Registered Nurses], faculty and nurse faculty).

- Nursing theory: Two theories and theory in general are more mentioned in the United States (human becoming, Parse (person), nursing theory and Roy Adaptation Model).

- Research methods: Three research methods are more used in the United States (community-based participatory research, concept analysis and instrument development).

- Social perspectives about health: Wider social issues surrounding the health of individuals seem to be discussed more in the United States (health disparities, women's health, health literacy, global health, disparities, environmental health, diversity, transcultural health, health policy and Africa).

- Technology in nursing: Computing technology seems to be more mentioned in the United States (informatics, nursing informatics, technology and health information technology), including one application (teledermatology).

- Treatment, care, diagnostic tools: Several of these are more discussed in the United States (physical activity, exercise, contraception, DNP [DiNitroPhenol diet drug], symptom management, prenatal care, hospice, cesarean birth, radiation therapy, vaccine, mammography, caregiver, self-care and medication adherence).

- Generic: Two terms had multiple uses (nursing science and elementary).

\section{DISCUSSION}

From the first research question, analysing the journals in which a nation's nurse researchers publish does not reveal national specialties. Although many journals focus on specialisms (e.g., Nursing Management and Journal of Pediatric Nursing), they usually attract authors mainly from the host country. A practical implication is that national areas of nurse research can only be detected by analysing at the article level and not at the journal shares level (e.g., the fact that $0 \%$ of articles in the Clinical Journal of Oncology Nursing are from Ireland, New Zealand and the United Kingdom is irrelevant to whether oncology nursing is researched in these countries).

The second and third research questions addressed text processing strategies to extract words or phrases from article titles, abstracts and keywords to help identify relevant international topic differences. The alternative NLP techniques that were tried each yielded complementary information, but the key phrase comparison gave a manageable set of relatively unambiguous terms to report and was therefore superior to reporting keywords. Both POS tagging and lemmatisation gave useful additional results, but NER was unhelpful. 
The fourth (and main) research question concerned international differences in nursing research topics, finding 130 words or phrases that were statistically significantly more common in US-authored journal articles than in the remaining countries. Although the existence of any differences confirms that international nursing research is not homogeneous, the breadth of coverage of the terms suggest that there are substantial and widespread differences in the research foci between nations, even when they have a shared language and similar level of economic development.

\section{1 | Limitations}

This article is limited by the sample and analysis methods. The sample does not encompass all nursing articles because Scopus is not comprehensive, and nursing articles appear in journals not matching the search criteria. The term frequency method is not robust because of the nonindependence of the choice of topic for different papers. There may also be international differences in terms used for concepts so that statistically significant terms may reflect differences in language use rather than underlying differences. Polysemy also affects the power of the method, as does the extent to which there is an agreed and stable expression for a concept. The number of articles for each country also influences statistical power, so finer-grained differences can be identified for countries with more nursing articles. Moreover, as the overlaps between different analysis methods showed, the standard keyword method does not give an exhaustive list of international differences. Thus, the terms extracted form an incomplete list.

\section{5 | CONCLUSIONS}

From a methodological perspective, it is clear that keyword and phrase differences are useful to reveal international differences in nursing research topics and are recommended for future studies. The results suggest that there are numerous differences between nursing research in English-speaking countries. In addition to demographicrelated variations, these differences include patient groups, biochemistry, education, skills, management, roles, research methods, theory, technology and social perspectives. Researchers should examine these differences to put their work in context and identify topics that are overlooked in their own country, despite receiving attention in others. Such topics, if nationally relevant, are logical choices for future study both to identify any national particularities and to ensure that relevant knowledge is applied in the host country's nursing practice.

\section{ACKNOWLEDGEMENT}

None declared.

\section{CONFLICT OF INTEREST}

The authors declare no conflict of interest.

\section{AUTHORSHIP STATEMENT}

Mike Thelwall designed the study, collected the data and prepared the first draft of the manuscript. Amalia Mas-Bleda realized a content analysis of the bibliometric studies and revised the manuscript critically for important intellectual content. All authors approved the final version for submission.

\section{ORCID}

Mike Thelwall (D) https://orcid.org/0000-0001-5927-424X

Amalia Mas-Bleda (D) https://orcid.org/0000-0002-2284-0161

\section{REFERENCES}

Arzuaga, M. A., Correa, A. H., \& Florez-Torres, I. E. (2015). Production of knowledge in the master's program in collective health of the Faculty of Nursing at Universidad de Antioquia, 1996-2013. Investigación y Educación en Enfermería, 33(2), 206-216. https://doi.org/10.1590/ S0120-53072015000200003

Backes, V. M. S., do Prado, M. L., Lino, M. M., Ferraz, F., Canever, B. P., Gomes, D. C., \& Martini, J. G. (2013). Theses and dissertations of nurses about education in nursing and health: A bibliometric study. Revista Brasileira de Enfermagem, 66(2), 251-256. https://doi.org/10. 1590/S0034-71672013000200015

Baggio, M. A., Rodrigues, M. A., Erdmann, A. L., Barbieri Figueiredo, M. D. C. A., \& Vieira, M. M. D. S. (2014). Production of nursing thesis and dissertations in Portugal, 2000-2010: A bibliometric study. Texto \& Contexto - Enfermagem, 23(2), 250-260. https://doi.org/10.1590/ 0104-07072014002190012

Bagnasco, A., Watson, R., Barisone, M., Pellegrini, R., Timmins, F., Aleo, G., \& Catania, G. (2019). The development of nursing research ten years after the establishment of PhD Schools of Nursing in Italy. Professioni Infermieristiche, 72(3), 165-170. https://doi.org/10.7429/ pi.2019.723165

Benjamini, Y., \& Hochberg, Y. (1995). Controlling the false discovery rate: A practical and powerful approach to multiple testing. Journal of the Royal Statistical Society: Series B: Methodological, 57(1), 289-300. https://doi.org/10.2307/2346101

Benton, D. C., \& Alexander, M. (2016). The Journal of Nursing Regulation at age 6: A bibliographic analysis. Journal of Nursing Regulation, 7(2), 4-8. https://doi.org/10.1016/S2155-8256(16)31072-9

Benton, D. C., Catizone, C. A., Chaudhry, H. J., DeMers, S. T., Grace, P., Hatherill, W. A., \& Monahan, M. J. (2018). Bibliometrics: A means of visualizing occupational licensure scholarship. Journal of Nursing Regulation, 9(1), 31-37. https://doi.org/10.1016/S2155-8256(18)30052-8

Benton, D. C., Cusack, L., Jabbour, R., \& Penney, C. (2017). A bibliographic exploration of nursing's scope of practice. International Nursing Review, 64(2), 224-232. https://doi.org/10.1111/inr.12337

Benton, D. C., Trautman, D. E., \& Swick, M. (2017). Healthcare transformation: A bibliometric analysis of a global endeavor. OJIN: The Online Journal of Issues in Nursing, 22(2) Manuscript 5. https://doi.org/10. 3912/OJIN.Vol22No02Man05

Berk, R. A., Western, B., \& Weiss, R. E. (1995). Statistical inference for apparent populations. Sociological Methodology, 25, 421-458. Retrieved from. https://www.jstor.org/stable/271073

Borracci, R. A., \& Rabhansl de Desmery, M. M. (2013). The production of Medline indexed articles on nursing research in Latin America. Argentine Journal of Cardiology, 81(5), 422-426. https://doi.org/10.7775/ rac.v81.i5.2060

Brill, E. (1992). A simple rule-based part of speech tagger. In M. Bates, \& O. Stock (Eds.), Proceedings of the Third Conference on Applied Natural Language Processing (pp. 152-155). New York, NY: Association for Computational Linguistics. 
Browne, N., Robinson, L., \& Richardson, A. (2002). A Delphi study on the research priorities of European oncology nurses. European Journal of Oncology Nursing, 6(3), 133-144. https://doi.org/10.1054/ejon.2002. 0191

Bu, Y., Ni, S., \& Huang, W.-B. (2017). Combining multiple scholarly relationships with author cocitation analysis: A preliminary exploration on improving knowledge domain mappings. Journal of Informetrics, 11(3), 810-822. https://doi.org/10.1016/j.joi.2017.06.004

Cecil, R., Thompson, K., \& Parahoo, K. (2006). The Research Assessment Exercise in nursing: Learning from the past, looking to the future. Journal of Advanced Nursing, 15(4), 395-402.

da Silva, P. P., dos Santos Oliveira, M., Spindola, T., Xavier, M. L., de Oliveira, D. C., \& Franco, V. Q. (2016). Análise das dissertações de mestrado em enfermagem da Universidade do Estado do Rio de Janeiro [Analysis of the dissertations of master's degree in nursing of State University of Rio de Janeiro]. Revista Enfermagem UERJ, 24(4), e18407. https://doi.org/10.12957/reuerj.18407

Damar, H. T., Bilik, O., Ozdagoglu, G., Ozdagoglu, A., \& Damar, M. (2018). Evaluating the nursing academicians in Turkey in the scope of Web of Science: Scientometrics of original articles. Scientometrics, 115(1), 539-562. https://doi.org/10.1007/s11192-018-2641-x

de Holanda, E. R., Lira, M. D. C. C., Galvão, M. T. G., Damasceno, M. M. C., \& de Araujo, T. L. (2013). Tendencies in the production of scientific knowledge in nursing regarding HIV/AIDS: A bibliometric study. Online Brazilian Journal of Nursing, 12(4), 986-997. https://doi.org/10.5935/1676-4285.20133818

Drennan, J., Meehan, T., Kemple, M., Johnson, M., Treacy, M., \& Butler, M. (2007). Nursing research priorities for Ireland. Journal of Nursing Scholarship, 39(4), 298-305. https://doi.org/10.1111/j.1547-5069.2007. 00184.x

Dupin, C. M., Chami, K., Petit dit Dariel, O., Debout, C., \& RothanTondeur, M. (2013). Trends in nursing research in France: A crosssectional analysis. International Nursing Review, 60(2), 258-266. https://doi.org/10.1111/inr.12020

Falagas, M. E., Pitsouni, E. I., Malietzis, G. A., \& Pappas, G. (2008). Comparison of PubMed, Scopus, Web of Science, and Google Scholar: Strengths and weaknesses. The FASEB Journal, 22(2), 338-342. https://doi.org/10.1096/fj.07-9492LSF

Ferreira, M. A. L., Pereira, A. M. N. D. A., Martins, J. C. A., \& BarbieriFigueiredo, M. D. C. (2016). Palliative care and nursing in dissertations and theses in Portugal: A bibliometric study. Revista da Escola de Enfermagem da USP, 50(2), 313-319. https://doi.org/10.1590/S0080623420160000200019

Kokol, P., \& Vošner, H. B. (2017). Nursing informatics research: A bibliometric analysis of funding patterns. Online Journal of Nursing Informatics, 21(2) Retrieved from. http://www.himss.org/ojni

Kokol, P., \& Vošner, H. B. (2019). Historical, descriptive and exploratory analysis of application of bibliometrics in nursing research. Nursing Outlook, 67(6), 680-695. https://doi.org/10.1016/j.outlook.2019. 04.009

Kokol, P., Železnik, D., Završnik, J., \& Blažun Vošner, H. (2019). Nursing research literature production in terms of the scope of country and health determinants: A bibliometric study. Journal of Nursing Scholarship, 51(5), 590-598. https://doi.org/10.1111/jnu.12500

Larivière, V., Desrochers, N., Macaluso, B., Mongeon, P., Paul-Hus, A., \& Sugimoto, C. R. (2016). Contributorship and division of labor in knowledge production. Social Studies of Science, 46(3), 417-435. https://doi. org/10.1177/0306312716650046

Leydesdorff, L., \& Nerghes, A. (2017). Co-word maps and topic modeling: A comparison using small and medium-sized corpora $(\mathrm{N}<1,000)$. Journal of the Association for Information Science and Technology, 68(4), 1024-1035. https://doi.org/10.1002/asi.23740

Lu, Y., Li, Z., \& Arthur, D. (2014). Mapping publication status and exploring hotspots in a research field: Chronic disease self-management. Journal of Advanced Nursing, 70(8), 1837-1844. https://doi.org/10.1111/jan. 12344

Manning, C., Surdeanu, M., Bauer, J., Finkel, J., Bethard, S., \& McClosky, D. (2014). The Stanford CoreNLP natural language processing toolkit. In K. Bontcheva, \& Z. Jingbo (Eds.), Proceedings of 52nd Annual Meeting of the Association for Computational Linguistics (pp. 55-60). Baltimore, MD: ACL.

Martín-Arribas, M. C., González-Gil, T., Egea-Zerolo, B., García, R. H., Mallada, C. J., \& Moreno-Casbas, T. (2009). Analysis of nursing research studies submitted to Spain's health research fund and the resulting scientific output. Journal of Research in Nursing, 14(2), 153-166. https://doi.org/10.1177/1744987108102006

Nadeau, D., \& Sekine, S. (2007). A survey of named entity recognition and classification. Lingvisticae Investigationes, 30(1), 3-26.

Polit, D. F., \& Beck, C. T. (2009). International differences in nursing research, 2005-2006. Journal of Nursing Scholarship, 41(1), 44-53. https://doi.org/10.1111/j.1547-5069.2009.01250.x

Straková, J., Straka, M., \& Hajič, J. (2014). Open-source tools for morphology, lemmatization, POS tagging and named entity recognition. In K. Bontcheva, \& Z. Jingbo (Eds.), Proceedings of 52nd Annual Meeting of the Association for Computational Linguistics: System Demonstrations (pp. 13-18). Baltimore, USA: ACL Press.

Sweileh, W. M., Huijer, H. A. S., Al-Jabi, S. W., Sa'ed, H. Z., \& Sawalha, A. F. (2019). Nursing and midwifery research activity in Arab countries from 1950 to 2017. BMC Health Services Research, 19(1), 340. https://doi. org/10.1186/s12913-019-4178-y

Talley, E. M., Newman, D., Mimno, D., Herr, B. W. II, Wallach, H. M., Burns, G. A., ... McCallum, A. (2011). Database of NIH grants using machine-learned categories and graphical clustering. Nature Methods, 8(6), 443-444. https://doi.org/10.1038/nmeth.1619

Tizón Bouza, E., Couto Caldelas, N., Álvarez Díaz, M., Marcos Espino, M. P., Eiroa Mejuto, M. E., Domínguez Blanco, V., \& Domínguez Soto, I. (2015). Human immunodeficiency virus: What has been published between 2008-2012 in Iberoamerica? Assessing nursing production. Revista ROL de enfermeria, 38(9), 30-39. Retrieved from:. http://www.e-rol.es

Waltman, L., Van Eck, N. J., \& Noyons, E. C. M. (2010). A unified approach to mapping and clustering of bibliometric networks. Journal of Informetrics, 4(4), 629-635. https://doi.org/10.1016/j.joi.2010. 07.002

White, H. D., \& McCain, K. W. (1998). Visualizing a discipline: An author co-citation analysis of information science, 1972-1995. Journal of the American Society for Information Science, 49(4), 327-355. https://doi. org/10.1002/(SICI)1097-4571(19980401)49:4<327::AID-ASI4>3.0. $\mathrm{CO} ; 2-4$

Wilkes, L., Cummings, J., Ratanapongleka, M., \& Carter, B. (2015). Doctoral theses in nursing and midwifery: challenging their contribution to nursing scholarship and the profession. Australian Journal of Advanced Nursing, 32(4), 6-14. Retrieved from. http://www.ajan.com.au/Vol32/ Issue4/1Wilkes.pdf

Wilkes, L., \& Jackson, D. (2011). Trends in publication of research papers by Australian-based nurse authors. Collegian, 18(3), 125-130. https:// doi.org/10.1016/j.colegn.2011.03.002

Ying, S., Jie, C., Ping, F., \& Lingjuan, Z. (2015). Bibliometric analysis of scientific articles on rehabilitation nursing for adult burn patients in China. Zhonghua Shao Shang Za Zhi = Chinese Journal of Burns, 31(3), 168-171.

Yue, L. Q., Pi, X. Q., \& Fan, X. G. (2016). Bibliometric analysis of scientific articles on evidence-based nursing of burn in the mainland of China. Zhonghua Shao Shang Za Zhi = Chinese Journal of Burns, 32(7), 442-446. https://doi.org/10.3760/cma.j.issn.1009-2587. 2016.07.016

Železnik, D., Blažun Vošner, H., \& Kokol, P. (2017). A bibliometric analysis of the Journal of Advanced Nursing, 1976-2015. Journal 
of Advanced Nursing, 73(10), 2407-2419. https://doi.org/10.1111/jan. 13296

Zhang, Y. Y., Zhu, L. L., Sheng, Y., Li, X. H., Xu, X. H., \& Wang, Q. Y. (2018). Disaster nursing development in china and other countries: $A$ bibliometric study. Journal of Nursing Scholarship, 50(5), 567-576. https://doi.org/10.1111/jnu.12401

Zhao, J., Liu, X., Zhang, W., Xing, Y., Cho, S. W., \& Hao, Y. (2018). Evidence-based nursing outputs and hot spot analysis of the last 5 years in mainland China: Results of a bibliometric analysis. International Journal of Nursing Practice, 24(2), e12628. https://doi.org/10.1111/ijn. 12628

\section{SUPPORTING INFORMATION}

Additional supporting information may be found online in the Supporting Information section at the end of this article.

How to cite this article: Thelwall M, Mas-Bleda A. How does nursing research differ internationally? A bibliometric analysis of six countries. Int J Nurs Pract. 2020;e12851. https://doi. org/10.1111/ijn.12851 